\title{
GENC Entity 1
}

National Cancer Institute

\section{Source}

National Cancer Institute. GENC Entity 1. NCI Thesaurus. Code C123747.

A geopolitical entity designated by the Geopolitical Entities, Names, anc Codes Standard (GENC). 